ISSN 0001-6002/2002/44/1/27-33

A cta M édica Costarricense, $\bigcirc 2002$

Colegio de Médicos y Cirujanos

\title{
Diagnóstico directo de la mutación que causa el síndrome del cromosoma $X$ frágil. Experiencia en Costa Rica.
}

Patricia Cuenca-Berger ${ }^{1,2}$, Fernando Morales-Montero ${ }^{1,2}$, Isabel Castro-Volio

J ustificación y objetivo: el síndrome del cromosoma $X$ frágil es la principal causa de retardo mental hereditario. A fecta a 1:4 000 varones y a 1:6 000 mujeres. La mayoría de las personas afectadas aún no han sido diagnosticadas y en sus familias suele haber más de un miembro con "retardo mental de origen oscuro". Si estas personas conocieran el diagnóstico y el carácter hereditario del padecimiento, el asesoramiento genético adecuado y oportuno, podría contribuir a reducir la ocurrencia o la recurrencia de esta patología en las familias. El objetivo por lo tanto fue hacer diagnóstico directo de la mutación que causa el síndrome, para confirmar o descartar el diagnóstico clínico o citogenético en los probandos, para encontrar a los portadores y portadoras en las familias de estas personas y de esa manera poder brindar prevención a través del asesoramiento genético. M étodos: se realizaron los análisis moleculares mediante hibridaciones de Southern, con las sondas 0x1.9 y StB 12.3 previa digestión del ADN genómico con las enzimas Hind III, EcoRI y Eagl. A demás de confirmar la presencia 0 ausencia de la mutación completa en los afectados por el retardo mental, se ha determinado el tamaño de la premutación en algunos portadores y confirmado a individuos libres de mutación mediante el uso de la reacción en cadena de la polimerasa. Resultados: se han realizado estudios moleculares en niños con examen citogenético positivo (grupo uno, $\mathrm{N}=13$ ), sus familiares cercanos (grupo dos, $\mathrm{N}=30$ ) y niños referidos por maestros, pediatras y sicólogos (grupo tres, $\mathrm{N}=15$ ). En nueve de los niños del grupo uno se confirmó la presencia de la mutación completa del gen FM R 1, en los otros cuatro se descartó, al encontrarse resultados normales en todas las pruebas moleculares. En el grupo dos se encontraron dos mujeres con la mutación completa y doce personas con la premutación: un varón transmisor fenotípicamente normal y once mujeres portadoras. El resto de los familiares estudiados resultaron normales. En el grupo tres se detectó una niña con la mutación, el resto fueron normales, tanto mediante estudios citogenéticos como moleculares. Conclusión: el diagnóstico preciso de la mutación permite, por un lado el abordaje correcto de los niños afectados desde el punto de vista psicopedagógico. Por otro lado, la identificación de los portadores de premutaciones y de los individuos libres de la mutación en una familia donde está segregando la enfermedad permite un consejo genético preciso de acuerdo al hallazgo molecular. Los métodos moleculares, además de más exactos, resultan más baratos que los citogenéticos cuando se cuenta con un laboratorio equipado y el personal capacitado.

Descriptores: genética humana, diagnóstico molecular, FRAXA, cromosoma X, retardo mental hereditario, FM R 1, mutaciones inestables.

Recibido: 18 de diciembre, 2002

Aceptado para publicación: 22 de enero, 2002

Abreviaturas: FRAXA: síndrome del cromosoma frágil, CGG: citosina guanina guanina, CpG: dinucleótidos de citidina fosfato guanosina, A GG: adenina guanina guanina, PCR: reacción en cadena de la polimerasa.

Instituto de Investigaciones en Salud (INISA),

Escuela de B iología,

Escuela de Medicina, Ciudad Universitaria Rodrigo Facio, San José Costa Rica.

Correspondencia: Dra. Patricia Cuenca, INISA, Universidad de Costa Rica, 2060 San J osé; fax: (506) 207-5130;

correo electrónico: pcuenca@ cariari.ucr.ac.cr
El síndrome de cromosoma $X$ frágil (FRAXA) es la segunda causa genética de retardo mental y la forma más frecuente de retardo mental hereditario, con una frecuencia estimada de 1:4.000 en varones y 1:6.000 mujeres ${ }^{1}$. FRAXA es una anomalía hereditaria ligada al cromosoma $X$, causante de discapacidades que van desde grados variables de problemas de aprendizaje hasta retardo mental. Con frecuencia se asocian retrasos severos en el lenguaje, problemas de conducta, comportamiento semejante al autista, testículos agrandados, orejas grandes o prominentes, hiperactividad, retraso en el 
desarrollo motor y deficiente integración sensorial 2. Este síndrome es responsable de la mayoría de los casos de trastornos hereditarios en el desarrollo psicomotor. El defecto molecular consiste en una cantidad aumentada de repeticiones de la tripleta citosina guanina guanina (CGG) en una región no codificante del gen $F M R 1$, situado en la porción terminal del brazo largo del cromosoma X. Este síndrome segrega como dominante ligado al $X$ con penetrancia reducida, ya que ambos sexos, cuando acarrean la mutación $X$ frágil, pueden presentar deficiencia mental ${ }^{3}$.

En el ámbito molecular, la mayoría de los individuos con este síndrome presentan dos tipos de al teraciones asociadas con el locus FM R-1:

1. Una de estas alteraciones consiste en la metilación anormal de una región en $\mathrm{X}$ q27.3 rica en dinucleótidos de citidina fosfato guanosina $(\mathrm{CpG})$ región que pertenece a las secuencias reguladoras Ilamadas "islas C $\mathrm{pG}$ ". La metilación de tales regiones generalmente bloquea la expresión de los genes adyacentes ${ }^{3}$. La confirmación de que la metilación anormal se asocia con la manifestación de FRAXA fue la observación hecha por Steinbach y colaboradores ${ }^{4}$ de un varón mentalmente normal, portador de una mutación completa pero ausencia de metilación. Estudios posteriores de series de pacientes han mostrado que un 10 a $12 \%$ de los varones con un locus FMR 1 anormal pueden presentar mosaicismo en la metilación, y poseer coeficientes intelectuales normales o casi normal es ${ }^{5}$. También se ha informado lo contrario, es decir un varón con retardo mental severo, autismo e hiperactividad que al examen molecular mostró tener un al elo normal, de 28 repeticiones pero mosaico para la metilación. La hibridación de Southern presentó en este caso la banda normal para los varones de $2,8 \mathrm{~K}$ b y una banda adicional de $5,2 \mathrm{~Kb}$ correspondiente al ADN resistente a la digestión con Eagl, es decir metilado ${ }^{6}$.

2. La otra anormalidad encontrada involucra una amplificación de la tripleta CGG en la región 5 'del locus FM R-1 7 . EI análisis del tamaño de esta amplificación en personas normales ha mostrado un ámbito de variación de 6 a 50 repeticiones. En familias afectadas se han encontrado dos tipos de mutaciones 8: las Ilamadas premutaciones, que no tienen efectos fenotípicos en los portadores, independientemente de su sexo, las cuales involucran amplificaciones entre 52 hasta 200 repeticiones y las mutaciones completas, que se encuentran en los individuos afectados por el síndrome, formadas por más de 200 repeticiones 9 .

Esta amplificación es inestable, lo cual se traduce en variabilidad tisular, esto significa que el número de repeticiones es diferente en las células de un mismo individuo; y su tamaño varía también de una generación a otra. La transición del estado de premutación a mutación completa ocurre con una al ta frecuencia cuando se trata de la transmisión de una madre portadora a su hijo afectado. La frecuencia con que ocurre esta transición depende del tamaño de la premutación 9,10, y de las tripletas adenina guanina guanina ( $A G G$ ) intercaladas entre las C G G. L os al elos normales poseen dos tripletas A G G intercaladas, un tercio de los alelos con premutaciones poseen solo una tripleta $A G G$, y el resto no tienen ninguna. A lelos con repeticiones intercaladas por A GG han mostrado más estabilidad en las transmisiones que los fragmentos constituidos únicamente por $\mathrm{CGGS}^{11}$.

Excepcionalmente se han encontrado pacientes afectados por FRAXA, que poseen otro tipo de defecto molecular, las mutaciones de punto en las posiciones 304 y 367, cambian residuos del aminoácido isoleucina por asparragina en el dominio KH de la proteína FM RP, dominio importante en la función de la FMRP ${ }^{3}$. También se han descrito diferentes tipos de deleciones ${ }^{12}$.

La proteína FM RP, producto del gen FM R-1, está ausente en los pacientes afectados. Su función es participar en el transporte de ARN mensajeros desde el núcleo hacia los poliribosomas principalmente localizados en las dendritas proximales de las neuronas, donde participa en la traducción de las proteínas. Su afinidad es específica para A RNs que se expresan en células nerviosas, incluyendo su propio ARN. EI retardo mental es el resultado de anormalidades en la traducción de proteínas que dependen de FM RP para el transporte de sus ARNs y para su traducción ${ }^{13}$.

El diagnóstico del cromosoma $X$ frágil se realizaba inicialmente gracias a la expresión citogenética de un sitio frágil en $X$ q27.3 ${ }^{14}$ Esta prueba diagnóstica ha sido relativamente confiable en los laboratorios más eficientes y es efectiva en identificar varones afectados.. En mujeres, el estudio de los cromosomas ha sido mucho más problemático, y la expresión citogenética no es un buen indicador de condición clínica ni es la prueba ideal para portadores ${ }^{15}$. Un aumento anormal en el largo de una región de ADN del cromosoma $X$ produce debilitamiento de la cromatina en esa zona, lo cual citogené ticamente se traduce como un sitio frágil. Este sitio frágil se expresa como una laguna isocromatídica en el cromosoma metafásico que se ubica en la posición X q27.3 ${ }^{7,16}$. Esta manifestación citogenética, también conocida como marcador, se produce cuando la amplificación de la secuencia del A DN alcanza cierto tamaño.

A ctualmente existen diferentes sondas específicas para hacer diagnóstico directo de la mutación en los afectados mediante la hibridación de Southern. Con esta técnica es posible determinar amplificaciones de 80 o más repeticiones. Cuando los familiares de un individuo afectado demandan consejo genético, se hace necesario usar la reacción en cadena de la polimerasa (PCR), para diagnosticar los portadores de amplificaciones pequeñas, lo cual permite conocer exactamente el tamaño de la región amplificada. Combinando los dos métodos es posible discriminar entre el alelo normal, el alelo premutado y el alelo con la mutación completa.

Las alteraciones fenotípicas que produce esta amplificación del ADN son diversas, y se enmarcan dentro de un síndrome bien caracterizado Ilamado síndrome de cromosoma $X$ frágil 
o síndrome de M artin-B ell, en honor a J.P. M artin y a J. B ell, quienes delinearon el síndrome por primera vez en 1943 (una detallada descripción se encuentra en Castro \& Cuenca, 1996).

FRAXA ha sido detectado en todos los grupos étnicos mayoritarios ${ }^{3}$. El estimado de prevalencia total del síndrome, obtenido de estudios moleculares en Inglaterra varía de 1: 2 700 a 1: 5700 varones ${ }^{17}$,y es de 1: 4350 en A ustralia ${ }^{1}$. El análisis molecular ha permitido ahora el estudio de la prevaIencia de premutaciones en mujeres. Un estudio sistemático realizado en mujeres de la población general de Quebec encontró que 1:500 es portadora de un alelo mayor a las 66 re peticiones, y que 1:500 es portadora de un al el o con un tama ño entre 55 y 63 (zona gris). Estas últimas tienen un riesgo menor de sufrir inestabilidad meiótica que las primeras, por lo que tienen un riesgo menor de tener un niño afectado ${ }^{18}$.

M ientras no se pueda "curar" la condición de portador de la mutación, la prevención primaria de la ocurrencia de esta patología se basa en la asesoría genética adecuada y oportuna a los miembros de la familia afectada. Como ya hemos explicado, las limitaciones en este sentido que impone el diagnóstico únicamente citogenético, se logran superar gracias al análisis directo de la mutación mediante técnicas de amplificación e hibridación del ADN. Un estudio en Nueva Gales del Sur ha demostrado que en diez años de consejo genético se ha logrado bajar la incidencia de F RA X A a la mitad y restaurar la confianza reproductiva a los miembros de las familias afectadas ${ }^{20}$. La prevención secundaria 0 post-concepción se logra en los países donde se permite la interrupción del embarazo, mediante diagnóstico precoz, embrionario o fetal. A plicando las técnicas moleculares mencionadas, se ha conseguido el diagnóstico molecular, más exacto que el que se obtenía mediante el uso de técnicas citogenéticas ${ }^{21}$. En cuanto a prevención terciaria, el estudio a fondo de los pacientes con éste síndrome ha permitido plantear estrategias específicas para mejorar su funcionamiento intelectual y su adaptación social 22, de ahí la importancia de la confirmación molecular del diagnóstico clínico.

El tratamiento es sintomático mientras no se cuente con terapia de reemplazo de la proteína o terapia génica de este síndrome ${ }^{23,24}$.

El enfoque más útil en el tratamiento del síndrome $X$ frágil es el multidisciplinario y de conjunto, que debe incluir un maestro de educación especial, un terapeuta de lenguaje, un terapeuta ocupacional, un médico, un psicólogo y un consejero genético ${ }^{2}$.

Con el fin de contribuir a que los pacientes costarricenses afectados por FRAXA y sus familias puedan beneficiarse de las metodologías modernas que ofrece la biología molecular este trabajo tuvo como objetivos:

Establecer la presencia de mutaciones inestables en el gen FMR1, determinar el estado de metilación del mismo y la cantidad de repeticiones de la tripleta CGG en las personas portadores de premutación.

A sesorar a las familias en las que segrega esta patología para que conozcan lo mejor posible esta enfermedad (causa, consecuencias, pronóstico, posibilidades de tratamiento y/o rehabilitación, manejo apropiado de las secuelas concomitantes, riesgos de ocurrencia o de recurrencia, etc.), ayudarlas a adaptarse positivamente y estimular el abordaje preventivo del síndrome y de sus secuelas.

Fomentar el conocimiento de esta patología entre el personal de salud y entre las personas encargadas de la educación de estos niños, para contribuir a potencializar sus fortalezas, desarrollar sus áreas débiles y manejar adecuadamente sus problemas de conducta y de adaptación social.

Este trabajo muestra los primeros esfuerzos en Costa Rica para hacer diagnóstico directo de la mutación en niños bajo sospecha clínica de FRAXA y sus familiares cercanos.

\section{Materiales y métodos}

El protocolo de esta investigación fue conocido y estudiado por el Comité de ética del Hospital Nacional de Niños. LoS pacientes estudiados se clasificaron en: grupo uno, 13 probandos con examen citogenético positivo, ya sea estudiados previamente en el INISA o en otros laboratorios; grupo dos, $\mathrm{N}=30$, sus familiares cercanos y el grupo tres, constituido por niños referidos por maestros, pediatras y sicólogos ( $\mathrm{N}=$ 15). Siempre que un niño o niña fué referido para estudio, se procedió a explicar a los padres las características del síndrome y los beneficios que la familia podía recibir a través del estudio molecular. Se obtuvo el consentimiento informado, se construyó la genealogía de la familia y se invitó a participar a otros familiares.

Se obtuvo una muestra de sangre en anticoagulante $A C D$, se extrajo el ADN según el método tradicional ${ }^{25}$, se cuantificó y se realizaron digestiones con la, o las enzimas de restricción respectivas: Hind III o Eco RI y Eagl, dependiendo del tipo de hibridación a realizarse. En cada individuo se llevó a cabo una hibridación utilizando la sonda Ox.1.9 ${ }^{26}$ o la StB $12.3{ }^{27}$ posterior a la digestión sencilla con $\mathrm{H}$ ind III, para determinar el tamaño de la amplificación. Simultáneamente se llevó a cabo una hibridación con la sonda StB 12.3 posterior a una doble digestión, en la cual, además de determinar el tamaño, por adición de la enzima Eagl que discrimina el estado de la metilación, se determinó si el gen está activo o inactivo.

Con el fin de poder ofrecer la mejor información a los potenciales portadores de premutaciones se utilizó la reacción en cadena de la polimerasa (PCR), y la posterior electroforesis de los productos en geles de poliacrilamida desnatural izantes, según el método descrito por $\mathrm{Fu}^{9}$ en 35 familares de pacientes. También se hizo control de calidad de los resultados de la PCR mediante el uso de un analizador automático de ADN en 19 pacientes ${ }^{29}$. 
Una vez obtenidos los resultados moleculares se hicieron sesiones de consejo genético, en las cuales se explicó detalladamente y en lenguaje sencillo los resultados y las consecuencias en cada persona estudiada.

\section{Resultados}

Utilizando la metodología descrita, los individuos normales presentan una banda de $2,8 \mathrm{~Kb}$ cuando se utiliza la enzima Hind III y la sonda $0 \times 1.9$, bandas de mayor tamaño corresponden a amplificaciones. Cuando se usa la doble digestión y la sonda StB 12.3; según se puede observar en la figura 1; los varones normales presentan una banda de 2,8 y las mujeres normales presentan dos bandas, la de 2,8 correspondiente al alelo localizado en el cromosoma $X$ activo y la de 5,2 correspondiente al alelo localizado en el cromosoma $X$ inactivo y metilado (por lo tanto resistente a la digestión con la enzima Eag I). Las mujeres portadoras de premutaciones pequeñas pueden tener bandas de mayor tamaño en cualquie ra de los dos al elos. Sin embargo las portadoras de mutaciones completas generalmente presentan aumentado de tamaño el alelo de 5,6 ya que las amplificaciones grandes promueven la metilación.

De esta manerra, se obtuvieron 58 estudios moleculares de niños con sospecha clínica o con diagnóstico citogenético del síndrome del cromosoma $X$ frágil y de familiares cercanos de los niños con resultados positivos (cuadro 1 ).

En nueve niños del grupo uno se confirmó el diagnóstico de mutación completa del gen FMR1, en los otros cuatro se descartó al encontrarse resultados normales en todas las pruebas moleculares. Los nueve niños positivos habían sido diagnosticados mediante estudio de cromosomas en el INISA, IOS niños negativos son cuatro hermanos diagnosticados en otro laboratorio fuera de la U.C.R. LoS niños negativos para la mutación FRAXA se estudiaron también para FRAXE, otro retardo mental asociado a un marcador de fragilidad en el cromosoma X, resultando también negativos. Entre los familiares de estos niños (grupo 2) se encontraron dos mujeres con la mutación completa y doce personas con la premutación: un varón transmisor normal y once mujeres portadoras. El resto de los familiares $(\mathrm{N}=16)$ obtuvo resultados normales. En el grupo tres se detectó una niña con la mutación, el resto fueron normales, tanto mediante estudios citogenéticos como moleculares.

En la figura 2 se muestra la genealogía de una de las familias estudiadas, donde se puede observar que la mutación se inició en el abuelo, quien porta una premutación pequeña, de 58repeticiones, pero con capacidad de amplificarse, dando como resultado tamaños mayores en las hijas (II-1; II-3 y II9 con amplificaciones entre las 65 y 70 repeticiones; II-12 con 160 repeticiones y la II-8 con 62 repeticiones), en quienes el alelo siguió creciendo, posibilitando de esta manera el nacimiento de varoncitos afectados con retardo mental.

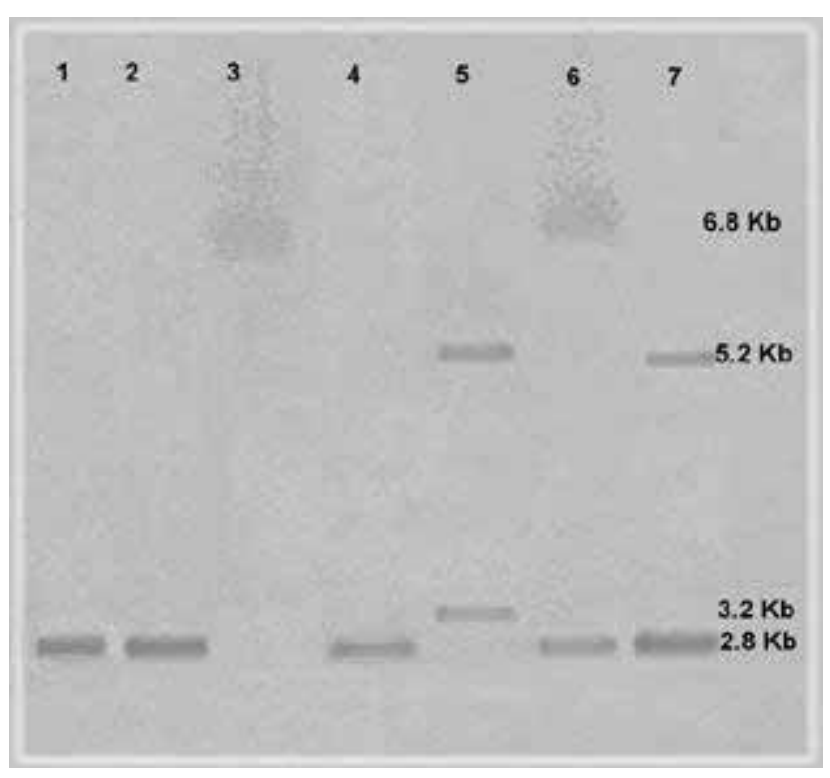

Figura 1: Autorradiografía de una hidridación de Southern con los análisis del ADN de siete pacientes. Los carriles 1,2 y 4 muestran tamaños de 2,8 kilobases correspondientes a varones normales. El carril 3 muestra una banda difusa de aproximadamente 6,6 kilobases pertenecientes a un varón afectado por FRAXA. En el carril 5 aparecen las bandas de una mujer portadora de una premutación, posee el alelo metilado normal de 5,2 kilobases y un alelo amplificado de 3,2 kilobases. Por último en el carril 7 se presentan las bandas de una mujer afectada con un alelo normal de 2,8 kilobases y el alelo metilado con una amplificación de 6,8 kilobases.

\section{Cuadro 1: Resultados moleculares en pacientes} con sospecha clínica de FRAXA y sus familiares.

\begin{tabular}{lccc} 
& Mujeres & Varones & $\begin{array}{c}\mathrm{N}^{\circ} \text { de repeticiones } \\
\text { CGG }^{*}\end{array}$ \\
\hline $\begin{array}{l}\text { Mutación completa } \\
\text { Premutación }\end{array}$ & 8 & 4 & $700-2900$ \\
Sin mutación & 11 & 1 & $58-200$ \\
- Sintomáticos & 2 & 16 & $19-35$ \\
- normales & 10 & 6 & $20-44$ \\
\hline
\end{tabular}

* Los tamaños hasta 58 repeticiones fueron establecidos exactamente por PCR, aquellos mayores fueron estimados de las hibridaciones de Southern. En los casos con mutación completa, para efectos de este cuadro se consignó el tamaño promedio de la banda observada.

\section{Discusión}

Este trabajo representa el primer informe en Costa Rica sobre resultados de estudios moleculares en pacientes afectados por el síndrome del cromosoma $X$ frágil y sus familiares. Estos estudios, han pasado a formar parte de la rutina en el diagnóstico y manejo de estos pacientes y sus familiares, desde comienzos de la década de los noventa, cuando se obtuvieron las sondas de ADN específicas para el gen FM R 1 , en los países desarrollados y algunos países en vías de desarrollo. 


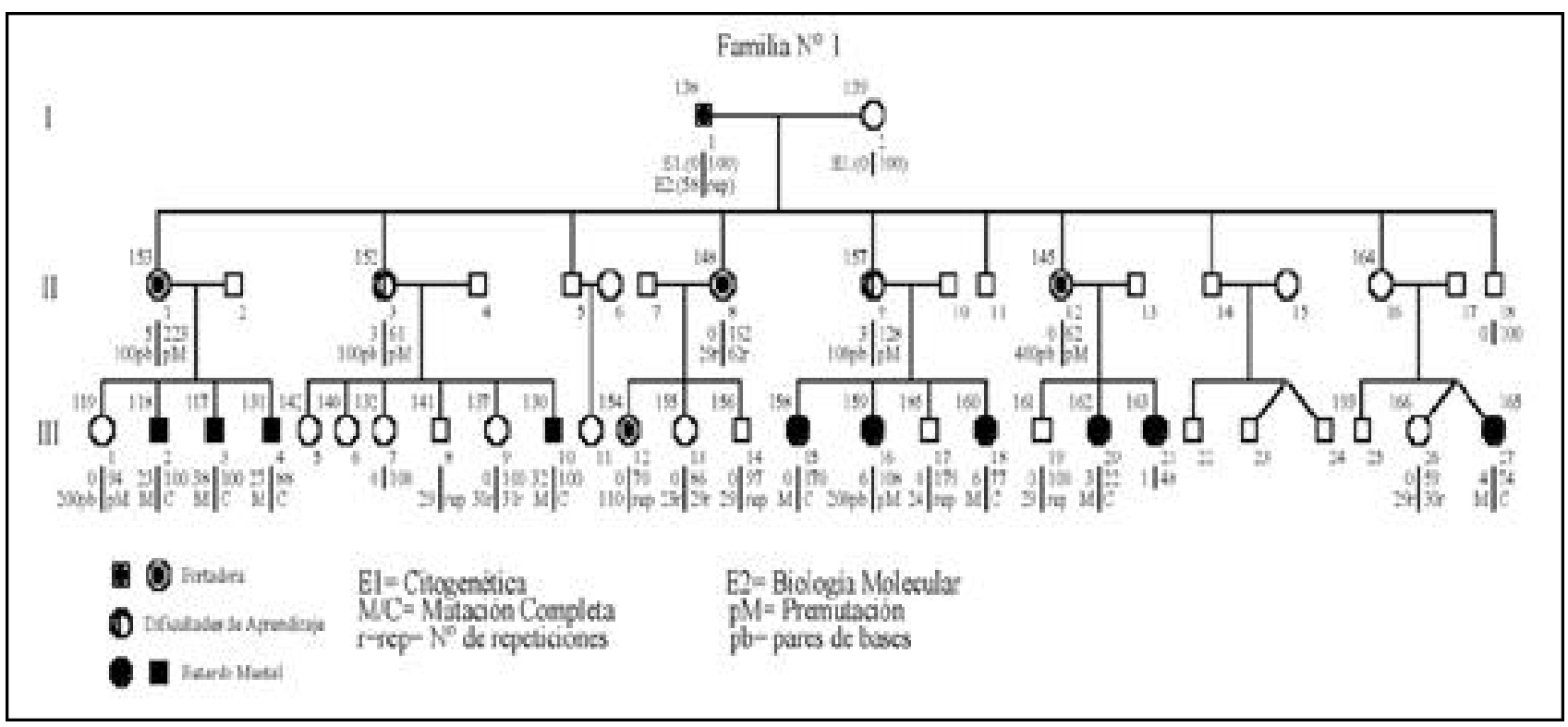

Figura 2: Genealogía de una de las familias estudiadas. Se puede observar que la amplificación del gen FMR1 comenzó en el abuelo materno con 58 repeticiones, quien heredó a sus hijas tamaños desde 65 hasta las 160 repeticiones de la tripleta CGG. De esta forma el gen se amplificó aún más en la tercera generación, dando como resultado varios varones afectados por retardo mental. Ver explicación en el texto.

L os resultados de este estudio demuestran la importancia de confirmar la sospecha clínica y/citogenética con la biología molecular antes de ofrecer el consejo genético a los pacientes ya que encontramos un diagnóstico negativo para la amplificación del gen FMR 1 en cuatro niños que fueron referidos por presentar el marcador cromosómico. El uso de la citogenética es limitado a los afectados por mutaciones completas y tiene el riesgo de arrojar resultados falsos positivos, que confundirán tanto al consejero como a la familia. EI hallazgo de resultados moleculares negativos para FRAXA en niños con retardo mental de causa desconocida y positivos para el marcador cromosómico es común en la literatura debido a la presencia de otros sitios frágiles en la porción distal del brazo largo del cromosoma $X^{29}$.

La prevención basada en el consejo genético es la forma más efectiva de enfrentar este síndrome. En Nueva Gales del Sur, A ustralia, (con una población de 6,5 millones de habitantes) por ejemplo, la tasa de incidencia ha bajado diez veces, de $4,3 / 10.000$ a 0,5/10.000 como consecuencia del programa de consejo genético, apoyado en diagnóstico prenatal e interrupción del embarazo ${ }^{20}$.

En Costa Rica, no existen datos sobre la inversión económica y social que representa para la sociedad y las familias afectadas, la atención de las personas discapacitadas. Sin embargo los pacientes afectados por FRAXA requieren atención y dedicación de otras personas durante toda su vida.

La esperanza de vida de los afectados y portadores es igual que la población general, las mujeres portadoras de premutación presentan un riesgo mayor de padecer menopausia precoz y trastornos afectivos.
Los niños oportuna y correctamente diagnosticados con el síndrome del cromosoma $X$ frágil se benefician con la adquisición de este conocimiento por parte de sus padres y de sus maestros ya que tienen características particulares que los diferencian de otros niños con retardo o dificultades de aprendizaje de otro origen. Estas peculiaridades hacen necesario un abordaje psicopedagógico especial, el cual ha tenido éxito probado en otros países y ha contribuido al desarrollo de los niños de manera que funcionen con la mayor independencia posible, en ambientes tan normales como es factible ${ }^{29}$. Por otro lado, la identificación de personas portadoras en las familias les permite tomar decisiones en cuanto a reproducción acorde a sus necesidades, circunstancias y valores. A demás para las personas sin esta mutación, el alivio de su preocupación respecto al riesgo de transmisión es grande.

En el cuadro 2 se resumen las recomendaciones internacionales vigentes para referir a los pacientes al laboratorio para estudio molecular del gen FM R 1 .

El Instituto de Investigaciones en Salud ofrece a la comunidad médica nacional y a las escuelas de enseñanza especial el servicio de diagnóstico molecular, y en los casos que ameriten las sesiones de consejo genético que sean necesarias con los familiares.

\section{Agradecimientos}

A I Prof.Dr. Jean-L uis M andel de la Universidad L uis Pasteur de Estrasburgo, Francia, por permitirnos el uso de la sonda StB 12.3 y al Prof. Dr. K ey Davies del Instituto de M edicina M olecular de Oxford, Inglaterra, por permitirnos usar su sonda Ox1.9. Al Organismo Internacional de Energía A tómica, la Comisión de Energía A tómica de Costa Rica y a la Vice- 
rrectoría de Investigación de la U niversidad de Costa Rica, proyecto $\mathrm{N}^{\circ}$ 742-95-257, por su apoyo financiero. A la señora R egina N eumann y al señor Federico Hernández por su apoyo técnico. A los Dres. Peter Nürnberg, Hartmut Peters, Peter Steinbach y Douglas Wilcox por su colaboración.

\section{Abstract}

Fragile $X$ syndrome is the most common hereditary type of mental retardation, affecting 1:4 000 males and 1:6 000 females. Unfortunately, most persons with this syndrome have not been diagnosed and are classified as cases of mental retardation of unknown origin. The correct etiological classification of these patients would allow their families to avoid recurrence of this disease through adequate genetic counseling. A s a result, this study intended to provide accurate molecular diagnosis of fragile $X$ syndrome in mentally retarded patients with clinical or cytogenetic suspicion of the disease, to detect the normal transmitting males and female carriers in each of the proband's families and to promote prevention after proper genetic counseling. To achieve this, genomic DNA was digested with Hind III, EcoRI and Eagl and Southern blotting was performed with probes $0 \times 1.9$ and StB 12.3. To asses the size of the trinucleotide repeat, PCR was used in some of the cases. Three groups were studied: group one with 13 children with the cytogenetic marker, 30 of their close relatives conformed group two and group three with 15 clinically suspicious fragile X syndrome children. R esults: of the 13 probands, four proved not to be fragile $X$ cases since their average repeat number was 30 . In group two, two females with the full mutation, one normal transmitting male and eleven female carriers with the premutation were found. In group three an additional female with the full mutation was identified, the rest had normal DNA and cytogenetic test results. In summary, DNA studies are a better way to accurately asses the full mutation and premutation carriers. The right diagnosis renders benefits to fragile $X$ cases in terms of the interventions they need and to carriers since this information is a must for proper genetic counseling and prevention. M oreover, molecular studies are cheaper than cytogenetic diagnosis in well equipped laboratories with trained personnel.

\section{Cuadro 2 Recomendaciones internacionales vigentes para solicitar el estudio molecular del gen FMR1.}

Población

Observaciones

Niños con retardo mental idiopático, autismo y trastornos del desarrollo

Niños con retardo mental y antecedentes familiares de retardo mental

Entre un 5 y $6 \%$ tienen mutación en FMR1

$30 \%$ de los retardos mentales ligados al cromosoma $X$ son FRAXA

Individuos con problemas de aprendizaje, déficit atencional y atraso en el lenguaje, con historia familiar de retardo mental $\mathrm{y} / 0$ rasgos fenotípicos concordantes con FRAXA

Síndromes: Soto, Prader-Willi, "secuencia Pierre Robin", de la Tourette con déficit cognoscitivo.

Mujeres en edad reproductora con historia familiar de retardo mental.

Cerca de la mitad de las mujeres con la mutación completa no tienen retardo mental.

Estos fenotipos se han asociado también con la mutación en FMR1

1:40 mujeres con historia familiar portan la mutación.

Tienen alto riesgo de portar la mutación.

El fenotipo de FRAXA puede incluir psicopatología y trastornos severos de conducta.
Pacientes psiquiátricos con trastornos de personalidad esquizoides con déficit social y manerismos.

Pacientes con psicosis asociadas a retardo mental, mutismo selectivo, severos trastornos de ansiedad 0 fobias sociales.

\section{Referencias}

1. Turner $G$, Webb T, Wake S, Robinson $H$. Prevalence of fragile $X$ syndrome. A m.J.M ed Genet. 1996: 64:196-97.

2. Hagerman R. Clinical and diagnostic aspects of fragile $X$ syndrome. En: Wells R Warren $S T$, Sarmiento $M$, ed. Genetic instabilities and hereditary neurological diseases. New York: A cademic Press. 1998: 15-25.

3. Imbert G, Feng Y, Nelson D L, Warren S T, M andel. 1998. FM R 1 and mutations in fragile $X$ syndrome: $M$ olecular biology, biochemistry, and genetics. En: Wells R Warren S T, Sarmiento M ed. Genetic instabi lities and hereditary neurological diseases. N ew Y ork: A cademic Press. 1998: 27-54

4. Wöhrle D, Salat U, Gläser D, M ücke J, M eisel-Stosiek M, Schindler $D$, et al. Unusual patterns of mutations in high functioning fragile $X$ males and other cases may result from instability of expanded CGG repeats in the absence of methylation. J.M ed.Genet. 1998: 35:103-111. 
5. Lachiewicz A M, Spiridigliozzi G A, M cConkie-R ossell A, Burhess D, Feng $Y, W$ arren $S T$ et al. A fragile $X$ male with a broad Smear on Sout hern blot analysis representing 100-500 CG repeats and no-methylation at the Eagl site of the FM R-1 gene. A m. J. Hum. Genet. 1996: 64: 278-282.

6. Battagia $P$, de Fanti, E, Grimau-M erino R, Giardina L, Schiavon R $L$ aboratory findings in a male with suspected $X$-fragile syndrome; $D$ iscovery of mosaicism of normal and methylated FM R-1 genes. Eur. J. Hum. Genet. 2001: 9, Supl 1: 172

7. Verkerk A J M, Pieretti M, Sutcliffe J S, Fu Y H, Kuhl D P, Pizzuti A, et al. Identification of a gene (FM R-1) containing a CGG repeat coincident with a breakpoint cluster region exhibiting length variation in fragile X syndrome. Cell: 1991:65 :905-914.

8. Oberlé I, R osseau F, H eitz D, K retz C, Deveys $D$ et al. Instability of a 550-base pair DNA segment and abnormal methylation in fragile $X$ syndrome. 1991:Science. 252:1097-1102.

9. Fu Y $H$, Kuhl D PA, Pizutti $A$, Pieretti $M$, Sutcliffe J $S$, Richards $S$ et al. Variation of the $C G G$ repeat al the fragile $X$ site results in genetic instability: resolution of the Sherman paradox. Cell. 1991: 67 :10471058

10. Yu S, Pritchard $M, K$ remer $E, L$ ynch $M, N$ ancarraw J, B aker $E$, et al. F ragile $X$ genotype characterized by an unstable region of DNA. Science. 1991: 252:1179-81.

11. Eichler E E, Holden J J A, Popovich B W, Reiss A L, Snow K, Thibodeau $S N$, et al. Length of uninterrupted CGG repeats determines stability in the FM R 1 gene. N ature Genet. 1994: 8: 88-94

12. Quan $F$, Zonana J, Gunter $K$, Peterson $K$ L, M agenis R.E, Popovich $B$ $W$. A $n$ atipical case of fragile $X$ syndrome caused by a deletion that in cludes the FM R 1 gene. 1995: A m.J.H um.Genet. 56 :1042-1051.

13. J in $\mathrm{P}$, Warren $\mathrm{ST}$. Understanding the molecular basis of fragile $\mathrm{X}$ syndrome. Hum M ol Genet. 2000: 9:901-908.

14. Castro I, Cuenca P. Frecuencia del síndrome del cromosoma $X$ frágil en la Escuela de Enseñanza Especial "Fernando Centeno Güell" A ct Ped Cost 1996:10(2):99-106.

15. Tommerup N. Cytogenetics of the fragile site at Xq27. En: Davies $K$ $E$. ed. The fragile $X$ syndrome. Oxford: Oxford University Press, 1989:102-135

16. Krawcsun $M S$, Jenkins $E C, B$ rown $W T$. A nalysis of the fragile $X$ chromosome: localization and detection of the fragile site in high resolution preparation. Hum Genet 1985: 69:209-211.

17. M orton J E, B undey S, Webb T P, M acD onald F, Rindl PM, Bullock S. Fragile $X$ syndrome is less common than previously estimated. J M ed Genet. 1997:34:1-5

18. Rousseau F, R ouillard P, M orel M L, K handjian E W, M organ K. Prevalence of carriers of premutation.size alleles of the FMR 1 gene and implications for the population genetics of the fragile $X$ syndrome. A m J Hum Genet 1995:57: 1006-1018.

19. Falik-Zaccai T C, Shachak E, Y alon M, L is Z, B orochowitz Z, M acPherson $J N$, et al. Predisposition to the fragile $X$ syndrome in Jews of Tunisian descent is due to the absence of AGG interruptions on a rare M editerranean haplotype. A m J Hum G enet 1997:60:103-112.

20. Turner $G$, Robinson $H$, Wake $S$, Laing $S$, Partington $M$. Case finding for the fragile syndrome and its consequences. B M J 1997:315: 12231226.
21. Sutherland G R, Gedeon A, Korman L, Donnelly A, Byard R W, M Ulley J $C$ et al. Prenatal diagnosis of fragile $X$ syndrome by direct detection of unstable DNA sequence. N Engl J M ed 1991: 325: 1720-1722.

22. Spiridigliozzi $G A$, Lachiewicz $M, M$ acM urdo $C S$, Vizoso $A D$ $O$ 'D onnel C M, M cConkie-Rossel A, et al. Educating boys with fragile X syndrome. A Guide for parents and professionals. Duke U niversity Medical Center. 1994: 1-20

23. Hagerman R J. Medical follow-up and pharmacotherapy. En: Hagerman $R$ J , Cronister A eds. Fragile $X$ syndrome diagnosis, treatment and research. B altimore: The J ohn Hopkins U niversity Press. 1996. 3-250.

24. Sobesky W E. The treatment of emotional and behavioral problems. En: Hagerman R J , Cronister $A$ eds. Fragile $X$ syndrome diagnosis, treatment and research. B altimore. The J ohn Hopkins U niversity Press. 1996: 332-340.

25. Strauss W M. Preparation of genomic DNA from mammalian tissue. En: A usubel F M, B rent R, Kinston R E eds. Current protocols in molecular biology. N ew York: J ohn Wiley and Sons Inc.1988:1:2.2.1-2.2.3

26. Snow K, Doud L, Hagerman R, Hull C, Hirst M C, Davies K E, et al A nalysis of mutations at the fragile $X$ locus using the DNA probe 0x1.9. A m J M ed Genet 1992:43:244-254.

27. Rousseau F D, Heitz D, B iancalana S, B lumenfeld C, K retz J, B oué J, et al. Direct diagnosis by DNAA nalysis of the fragile $X$ syndrome of mental retardation. N Engl J M ed 1991:325( ):1673-1681.

28. Larsen LA, Gronskov K, Norgaard-Pedersen B, B rondum-Nielsen K Hasholt $\quad L, V$ uust). High-throughput analysis of fragile X (CCG)n alleles in the normal and premutation range by PCR amplification and automated capillary electrophoresis. Hum Genet 1997:100: 564-568

29. A rrieta I, Criado B, M artínez B, Telez M, N uñez T, Panagarikano O, et al. A survey of fragile $X$ syndrome in a sample from Spanish $B$ asque country. Ann Genet 1999:42:197-201.

30. B raden $M$. Fragile, handle with care. Understanding fragile $X$ syndrome. Chapel Hill: Avanta Publishing Company. 1996:1-169. 